\title{
Prenatal alcohol exposure and offspring hyperactivity: The effects of home-cage shavings and test chamber temperature
}

\author{
NIGEL W. BOND \\ Macquarie University, North Ryde, New South Wales, Australia
}

\begin{abstract}
Rats were fed a liquid diet containing alcohol from Days 6-19 of gestation. Controls were pairfed the same diet with sucrose substituted for ethanol, or were allowed ad-lib chow and water. The activity of the offspring was observed in isolation at 10,16,22, or 28 days of age. Offspring exposed to alcohol prenatally were hyperactive relative to controls at 16 and 22 days, but not at 10 or 28 days. The presence of home-cage shavings in the test chamber affected the activity of the three groups similarly. In a second study, isolation-induced activity was observed at a test room temperature of $23^{\circ}$ or $33^{\circ} \mathrm{C}$. Offspring exposed to alcohol were hyperactive in comparison with pair-fed controls, at both 16 and 22 days, when tested at $23^{\circ} \mathrm{C}$. However, the difference in activity was attenuated at 16 days and abolished at 22 days if pups were tested at $33^{\circ} \mathrm{C}$. These findings indicate that the hyperactivity displayed by alcohol-treated offspring may be due in part to their experiencing greater thermal stress when removed from their dam and littermates.
\end{abstract}

Alcohol has been recognized as a teratogen since the reports of Lemoine, Harousseau, Borteryu, and Menuet, (1968) and Jones, Smith, Ulleland, and Streissguth (1973). Children diagnosed as evidencing the Fetal Alcohol Syndrome (FAS) invariably display mental retardation and, in a majority of cases, hyperactivity (Landesman-Dwyer, Ragozin, \& Little, 1981; Shaywitz, Cohen, \& Shaywitz, 1980 ). Although the mental retardation is clearly devastating to the child, the hyperactivity may be of more interest in delineating the mechanisms underlying the effects of fetal alcohol exposure (Bond, 1981, 1984). Unfortunately, various confounding factors have prevented us from learning much about such mechanisms from human studies (Abel, 1981), but they have been explored with work based upon animal models (Abel, 1981; Bond, 1981; Riley, 1982).

A review of the literature relating to fetal alcohol exposure and hyperactivity in rats (Bond, 1981) indicated that if dams are exposed to doses of alcohol of greater than $6-7 \mathrm{~g} / \mathrm{kg}$ per day during the period of organogenesis, and the pups are tested on a measure of activity prior to approximately 70 days of age, the pups display an increase in activity compared with control offspring. These findings suggest that the hyperactivity may result from the alteration of a normal developmental process (Bond,

This research was supported by Grant 401019 from the National Health and Medical Research Council. Thanks are extended to Ron Claasens and Wayne McTegg for their valuable technical assistance, to George Connor, Len Glue, and Ernie Venturato for maintaining the equipment, and to Louise Laffan, Fiona Lewis, and Craig Smith for assistance with the scoring of the videotapes. Judi Homewood and Dave Siddle provided comments upon an earlier version of the manuscript. Reprints may be obtained from Nigel W. Bond, School of Behavioural Sciences, Macquarie University, North Ryde, N.S.W. 2113, Australia.
1981, 1984). For example, during the course of normal development, the young rat passes through a stage of extreme hyperactivity if it is isolated from the rest of the litter (Campbell, Lytle, \& Fibiger, 1969). A number of external factors are known to influence this isolationinduced hyperactivity displayed by preweanling rats. For example, the hyperactivity is attenuated by the presence of siblings and/or an adult rat (Campbell \& Raskin, 1978). Furthermore, the presence of home-cage shavings in the test chamber may affect the hyperactivity, either abolishing it, if the test period is long (Campbell \& Raskin, 1978), or enhancing it, if the test period is short (BuelkeSam, Sullivan, Kimmel, \& Nelson, 1984; Pappas, Vickers, Buxton, \& Pusztay, 1982). Finally, if the pup is separated from its littermates and placed in an environment at or above $33^{\circ} \mathrm{C}$ (thermoneutrality for the preweanling rat pup), it may not show an increase in activity unless it is isolated for several hours (Bronstein, Marcus, \& Hirsch, 1978; Campbell \& Raskin, 1978; Goodrick, 1975).

The two experiments reported here were designed to provide information about the effects of fetal alcohol exposure on the ontogenetic changes observed in isolationinduced activity, and to examine the influence of homecage shavings and environmental temperature on such activity.

\section{EXPERIMENT 1}

The first experiment examined the effects of home-cage shavings on isolation-induced hyperactivity following fetal alcohol exposure. Isolation-induced activity was examined at $10,16,22$, or 28 days of age, in the presence of homecage shavings, clean shavings, or no shavings. (Note that 
16 days was chosen on the basis of considerable pilot work that had indicated that this was the age of peak hyperactivity in the strain employed in these studies.)

\section{Method}

Subjects. A total of 75 Wistar rats and their 413 pups were employed in Experiment 1. These animals were part of a continuous breeding program and were treated as follows. Each Sunday, four marked females were placed with two males in breeding cages $(33.5$ $\times 40 \times 25 \mathrm{~cm}$ high) located in a temperature-controlled room (26$27^{\circ} \mathrm{C}$ ) on a 12-h light/dark cycle, with lights on at $0700 \mathrm{~h}$. A vaginal smear was obtained from females at $0800 \mathrm{~h}$ each morning until they gave a positive smear, that is, presence of sperm in the smear, or until they were removed on the following Friday. Laboratory chow and water were freely available at all times.

On the day that they gave a positive smear, the females were weighed and housed individually in plastic wire-topped cages $(27 \times$ $38 \times 15 \mathrm{~cm}) \mathrm{kept}$ in a temperature-controlled room $\left(26-27^{\circ} \mathrm{C}\right)$, also on a 12-h light/dark cycle with lights on at $0700 \mathrm{~h}$. This day was designated as Gestation Day 1.

On Gestation Day 6, each female was weighed and assigned to one of the three groups, that is, to an alcohol, sucrose, or chow group. The alcohol group received a liquid diet containing by volume $5 \%$ ethanol $(95 \% \mathrm{v} / \mathrm{v}), 4.5 \%$ sucrose $(87 \% \mathrm{w} / \mathrm{v}), 87.5 \%$ Sustagen Sport $(0.95 \mathrm{Cal} / \mathrm{ml})$, and $3 \%$ water. The sucrose group was pairfed an equivalent liquid diet except for the isocaloric substitution of sucrose for the ethanol. Each rat received the amount consumed by her partner in the alcohol group on the previous day. The liquid diets were presented in Richter tubes to reduce spillage. The chow group received ad-lib laboratory chow and tap water. The animals received their respective diets until Gestation Day 19, when they were weighed and their diets were replaced with chow and tap water. The average dose of ethanol consumed by the alcohol dams during the last $24 \mathrm{~h}$ was $10.9 \mathrm{~g} / \mathrm{kg}$. The cages were then checked twice daily for the presence of offspring. When parturition was complete, the pups were counted, weighed, culled to four male and four female pups where possible, and returned to their biological mother.

The pups remained with their mother until testing, which took place when they were $10,16,22$, or 28 days of age. During this time, they were undisturbed except for routine changing of bedding, which took place at the above ages. Chow and water were available at all times.

Apparatus and Procedure. The activity of the pups was tested at $10,16,22$, or 28 days of age. For this, each pup was placed on its own in a small wire cage $(24 \times 14.5 \times 18 \mathrm{~cm}$ high) situated in a wooden sound-attenuating chamber fitted with a Perspex lid. The behavior of the pups was recorded via a television camera (Hitachi Denshi Ltd.) located directly above the chambers and connected to a time-lapse videotape recorder (Ikegami TVR321). When possible, a male and a female pup from each litter were tested for $6 \mathrm{~h}$ during the light portion of the light/dark cycle under one of three conditions: a test cage with no shavings, a test cage with clean pine shavings, or a test cage with dirty shavings from the pups' home cage. These shavings had been in the pups' home cage for 10 days (10-day-old pups) or 6 days (16-, 22-, or 28-day-old pups). The ambient temperature in the room was $23^{\circ} \mathrm{C}$. Videotapes were played back and activity was scored as a movement of all four paws across the shorter axis of the cage (Campbell \& Raskin, 1978).

\section{Results}

Characteristics of the dams and their litters. The characteristics of the dams and their offspring, combined across the two experiments, are shown in Table 1. The dams did not differ in weight on Day 1 of gestation $(\mathrm{F}<1)$, but they did differ in weight gain between Day 6 and Day $19[\mathrm{~F}(2,130)=29.8, \mathrm{p}<.001]$, with the chow
Table 1

Characteristics of the Dams and Their Litters

\begin{tabular}{|c|c|c|c|}
\hline & \multicolumn{3}{|c|}{ Group } \\
\hline & Alcohol & Sucrose & Chow \\
\hline Dams employed & 45 & 43 & 43 \\
\hline Pups employed & 245 & 234 & 245 \\
\hline $\begin{array}{l}\text { Body weight of dams (g) } \\
\text { Day } 1 \text { (gestation) }\end{array}$ & 281.1 & 275.1 & 272.8 \\
\hline $\begin{array}{l}\text { Weight gain }(\mathrm{g}) \\
\text { Days } 6-19\end{array}$ & 58.5 & 49.4 & 76.7 \\
\hline Length of gestation (days) & 24.0 & 23.6 & 23.4 \\
\hline Litter size (n) & 10.6 & 10.8 & 11.1 \\
\hline $\begin{array}{l}\text { Number of litters with } \\
\text { observed dead at birth (\%) }\end{array}$ & 46 & 43 & 27 \\
\hline Weight of pups at birth (g) & 5.7 & 5.6 & 5.8 \\
\hline Weights at 10 days & 20.2 & 21.1 & 20.9 \\
\hline Weights at 16 days & 31.5 & 32.3 & 34.4 \\
\hline Weights at 22 days & 50.5 & 51.2 & 51.1 \\
\hline Weights at 28 days & 71.3 & 72.2 & 75.6 \\
\hline
\end{tabular}

group gaining most weight and the alcohol group being intermediate between the chow and sucrose groups ( $p<.01$, chow vs. alcohol and alcohol vs. sucrose). There were no differences among the three groups in the number of dams carrying their pregnancies to term, but there was a difference in mean gestational length, the alcohol group evidencing a significantly longer gestation period $\left[\chi^{2}(2, N=131)=21.4, p<.01\right]$. There were no differences in mean litter size, mean litter weight at birth, or number of litters with observed dead at birth $(p>.05)$. To prevent overinflation of the degrees of freedom, the weight of the pups at the various test ages is expressed as the mean litter weight, irrespective of sex. As indicated in Table 1 and confirmed by statistical test, pups from the three groups did not differ in weight at any of the ages tested $(\mathrm{F}<1)$.

Prenatal ethanol exposure and isolation-induced activity: Effects of home-cage shavings. A five-way repeated measures analysis of variance was carried out on the activity scores summed over each $60 \mathrm{~min}$ of the 6-h test period [prenatal treatment (3) $\times$ age $(4) \times$ shavings $(3) \times \operatorname{sex}(2) \times$ test period (6)]. It yielded significant effects for prenatal treatment $[\mathrm{F}(2,341)=4.9$, $\mathrm{p}<.01]$ and age $[\mathrm{F}(3,341)=137.2, \mathrm{p}<.0001]$ and a significant prenatal treatment $\times$ age interaction $[F(6,341)=5.0, p<.001]$. Shavings did not occur as a main effect. Most importantly, shavings was not involved in any interaction with prenatal treatment. There was a significant effect of test period $[\mathrm{F}(5,1705)=34.2$, $\mathrm{p}<.0001]$ and test period interacted with age $[\mathrm{F}(17,1705$ $=20.4, \mathrm{p}<.0001]$ and shavings $[\mathrm{F}(10,1705)=6.6$, $\mathrm{p}<.0001]$. Finally, there was a significant three-way test period $\times$ age $\times$ shavings interaction $[F(30,1705)=$ $4.1, \mathrm{p}<.0001]$.

The interaction between prenatal treatment and age resulted from the greater activity of the alcohol-treated pups, particularly at 16 and 22 days of age $[t(341)>7.6$, $p<.005$, in all cases.] Tests of simple main effects indicated that the age effect was due to the greater activity of the 16-day-old pups in comparison with pups tested at 
other ages [t(341) $>20.9, \mathrm{p}<.005$, in all cases]. These findings are illustrated in Figure 1.

Given that the effects involving test period did not interact with prenatal treatment, they are not treated in any great detail. The period $\times$ age $\times$ shavings effect was due to the greater activity of the 16-day-old pups in the presence of shavings from their home-cage in comparison with both the clean-shavings and no-shavings conditions, only during the first hour of the test period ( $p<.05$ in both cases). The periods effect and its interaction with age were due to a decline in activity across the test period, particularly in the 16-day-old pups.

\section{Discussion}

The present data indicate that 16-day-old pups placed in isolation in a novel environment are considerably more active than 10-, 22-, or 28-day-old pups (Bronstein et al., 1978; Campbell et al., 1969). Most importantly, prenatal alcohol exposure led to an increase in this isolationinduced activity at 16 and 22 days of age. This basic finding accords with previous studies (Abel, 1982; Bond, 1984). Furthermore, the increase in activity had disappeared by 28 days of age. The transient nature of the increase is also in agreement with previous work (Abel, 1982; Bond \& DiGiusto, 1977).

Home-cage shavings enhanced the activity of 16-dayold pups in the first hour of the test as observed previously (Buelke-Sam et al., 1984; Pappas et al., 1982). However, in contrast to Campbell and Raskin (1978),

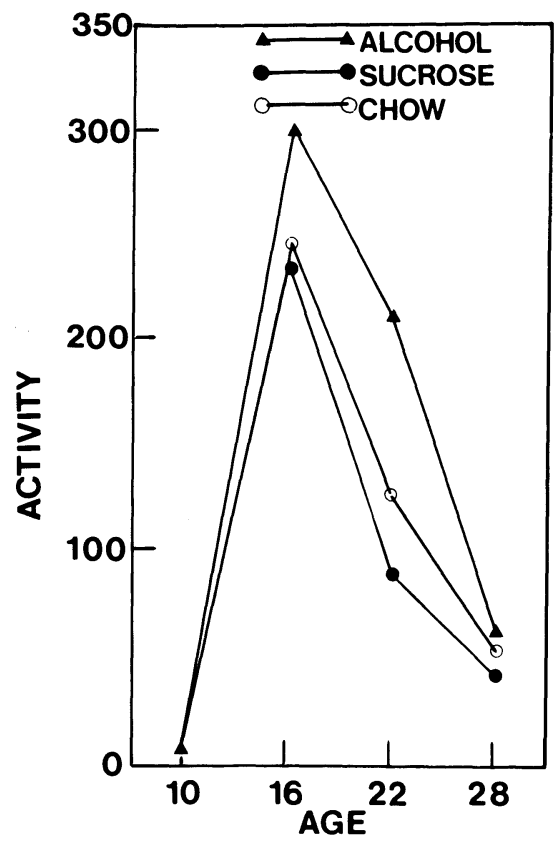

Figure 1. (Experiment 1) Activity of all three groups at 10, 16, 22 , and 28 days of age, totaled over the 6-h test period and collapsed across test-cage shavings. Pups whose dams consumed the alcohol diet (a) during Days 6-19 of gestation are denoted by the circles, those whose dams were pair-fed the sucrose diet (s) are denoted by the diamonds, and those whose dams were fed chow and water ad lib (c) are denoted by the triangles. home-cage shavings did not lead to an attenuation of activity over a long test period. Nevertheless, the alcohol group reacted to the presence of home-cage shavings in the test chamber in the same fashion as the sucrose and chow groups, as evidenced by the lack of any interaction between prenatal treatment and test cage shavings.

\section{EXPERIMENT 2}

Experiment 1 established that alcohol-treated pups display increases in isolation-induced activity at 16 and 22 days of age, and determined that the response evidenced by such pups to the presence of home-cage shavings is similar to that evidenced by control pups. Another factor known to influence isolation-induced activity is the ambient temperature in the test chamber. Thus, a number of authors have found that isolation-induced activity is attenuated by an increase in the ambient temperature, although it is not completely abolished (Bronstein et al., 1978; Campbell \& Raskin, 1978; Goodrick, 1975). The newborn rat is poikilothermic, and even at 22 days of age cannot defend its body temperature fully (Fowler \& Kellogg, 1975).

The findings outlined above have implications for the results of Experiment 1. It could be argued that the increase in isolation-induced activity observed in 16- and 22-day-old alcohol-treated pups was due to the fact that they were more subject to thermal stress and took longer to develop the ability to control their internal temperature than controls (Abel \& Greizerstein, 1979; Ewart \& Cutler, 1979; Randall, 1982). Thus, Experiment 2 was designed to examine the effects of ambient temperature on isolation-induced activity in alcohol-treated and control pups. Specifically, pups from the three groups were tested in the activity chambers at $10,16,22$, or 28 days of age at an ambient temperature of $23^{\circ}$ or $33^{\circ} \mathrm{C}$.

\section{Method}

Subjects. A total of $56 \mathrm{Wistar}$ rats and their 311 offspring were employed in this experiment. Housing and treatments were as described in Experiment 1.

Apparatus and Procedure. The basic procedure was as described in Experiment 1 with the pups being tested for $6 \mathrm{~h}$ in the activity chambers, at $10,16,22$, or 28 days of age, with clean shavings on the floor. Where possible a male and a female pup from each litter were tested with the test room at an ambient temperature of $23^{\circ}$ or $33^{\circ} \mathrm{C}$.

\section{Results}

Prenatal ethanol exposure and isolation-induced activity: Effects of environmental temperature. A fiveway repeated measures analysis of variance was carried out on the activity scores summed over each $60 \mathrm{~min}$ of the 6-h test period [prenatal treatment $(3) \times$ age $(4) \times$ temperature $(2) \times \operatorname{sex}(2) \times$ test period (6)]. It yielded significant effects of prenatal treatment $[\mathrm{F}(2,263)=17.0$, $\mathrm{p}<.001]$, age $[\mathrm{F}(3,263)=117.0, \mathrm{p}<.0001]$, and temperature $[F(1,263)=47.7, p<.0001]$. There were interactions between prenatal treatment and temperature $\mathrm{F}(2,263)=4.7, \mathrm{p}<.01]$, prenatal treatment and age 
$[\mathrm{F}(6,263)=7.8, \mathrm{p}<.001]$, and temperature and age $[F(3,263)=30.7, p<.0001]$. Finally, the effect of test period $[\mathrm{F}(5,1315)=20.4, \mathrm{p}<.0001]$ and the test period $X$ age $[F(15,1315)=8.6, p<.0001]$ and test period $\times$ temperature $\times$ age $[F(15,1315)=2.9, p<.0001]$ interactions were significant.

The interaction between prenatal treatment and age was due to the greater activity of the alcohol-treated pups at 16 and 22 days of age. Tests of simple main effects indicated that these differences were significant only in comparison with the pair-fed control group $[\mathrm{t}(263)>3.5$, $\mathrm{p}<.005$, in both cases]. The age effect was due to the greater activity of the 16-day-old pups in comparison with pups tested at 10,22 , or 28 days of age $[t(263)>4.5$, $\mathrm{p}<.005$, in all cases].

The age $\times$ temperature interaction resulted from the fact that the reduction in activity observed when the animals were tested at $33^{\circ} \mathrm{C}$ was greater in the 16 - and 22-day-old pups. The interaction of prenatal treatment with temperature was because the activity of all three groups was markedly reduced in the $33^{\circ} \mathrm{C}$ condition and the differences between them disappeared. This is confirmed by the finding that there was a prenatal treatment effect when pups tested in the $23^{\circ} \mathrm{C}$ condition were considered $[\mathrm{F}(2,128)=16.1, \mathrm{p}<.0001]$, but not when pups tested in the $33^{\circ} \mathrm{C}$ condition were considered $[\mathrm{F}(2,135)$ $=2.7, \mathrm{p}>.05]$. These findings are illustrated in Figure 2, which shows activity totaled over the 6-h test period in each group at each age.

The effects of test periods did not interact with prenatal treatment. As a result, they are not treated in any great detail. The interaction of periods with age and temperature was because the activity of pups tested at $33^{\circ} \mathrm{C}$ was attenuated in comparison with the activity of pups tested at $23^{\circ} \mathrm{C}$, and declined at a slower rate over the test ses- sion. The periods $\times$ age interaction was due to the fact that the rate of decline in activity was greater in the 16day-old pups.

\section{Discussion}

The temperature of the test environment had a profound influence on the isolation-induced activity of neonatal rats (see Figure 2). When pups were tested in isolation in a novel environment, their activity was attenuated if the environmental temperature was raised from $23^{\circ}$ to $33^{\circ} \mathrm{C}$. This effect was especially noticeable in 16-day-old pups; it was less so at 22 days and did not occur in 28-day-old pups. These results are in accord with previous findings (Bronstein et al., 1978; Campbell \& Raskin, 1978; Goodrick, 1975). They suggest that the hyperactivity seen in 16-day-old rat pups tested in a novel environment is due in part to thermal stress (Allin \& Banks, 1971).

In agreement with the findings of Experiment 1, the alcohol group, whose dams had received ethanol in their diets between Day 6 and Day 19 of gestation, were more active than controls at 16 and 22 days, although this difference was significant only when the alcohol group and the sucrose group were compared. (Since this disparity between the control groups was not observed in Experiment 1 , or in subsequent experiments carried out in our laboratory, it is assumed that it was due to random factors and it will not be dealt with further.)

Of greatest interest is the influence of test environment temperature on the activity differences. As illustrated in Figure 2, the differences between the groups disappeared in the $33^{\circ} \mathrm{C}$ condition due to the fact that activity was reduced in all groups at 16 and 22 days of age when in the warmer test environment. If the hyperactivity observed at 16 and 22 days is due to thermal stress, these data suggest that the alcohol group may be under more thermal

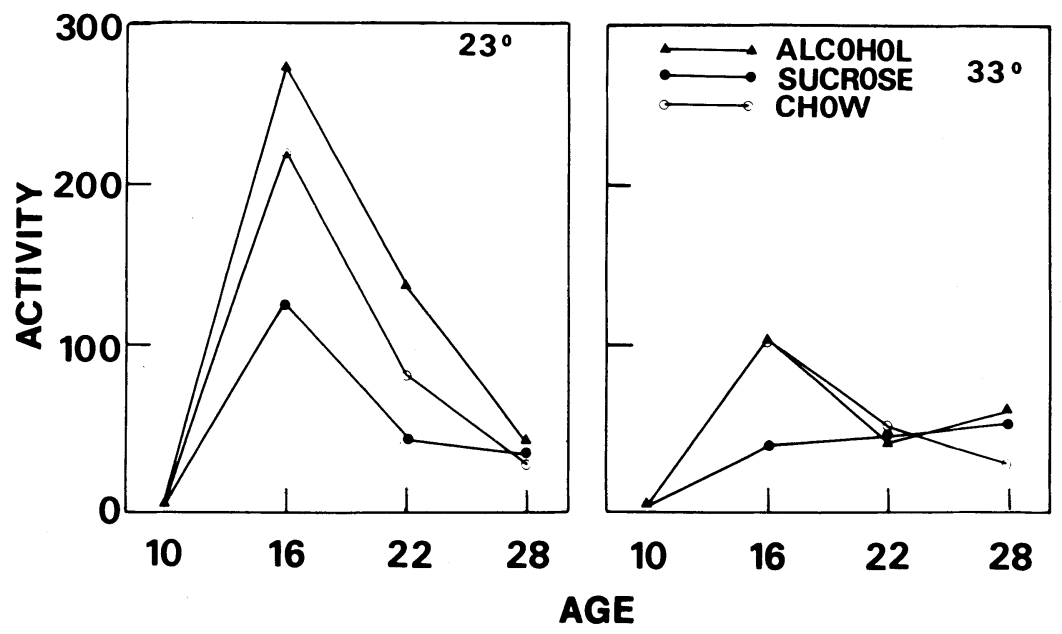

Figure 2. (Experiment 2) Activity of all three groups of pups at 10, 16, 22, or 28 days of age, totaled over the 6-h test period. Those tested at $23^{\circ} \mathrm{C}$ are shown at the left; those tested at $33^{\circ} \mathrm{C}$ are shown at the right. Pups whose dams consumed the alcohol diet during Days 6-19 of gestation are denoted by the triangles, those whose dams were pair-fed the sucrose diet are denoted by the filled circles, and those whose dams were fed chow and water ad lib are denoted by the open circles. 
stress than the controls. There is ample evidence of postnatal growth retardation in pups exposed to ethanol prenatally (Randall, 1982). Alterations in body composition (Abel \& Greizerstein, 1979) and delays in the growth of body fur (Ewart \& Cutler, 1979) have been observed. These findings suggest that alcohol-treated pups may be retarded in the ability to control body temperature. If the hyperactivity observed in normal 16-day-old pups is due in part to thermal stress, then alcohol-treated pups may be under even more stress and display even greater activity. In this context, it has been reported that newborn rat pups exposed to alcohol in utero have enlarged adrenal glands as well as elevated brain and plasma levels of corticosterone (Taylor, Branch, Cooley-Matthews, \& Poland, 1982). Furthermore, Taylor, Branch and Kokka (1981) have reported that rats exposed to alcohol prenatally display increases over controls in plasma levels of corticosterone following injection with $1.0 \mathrm{~g} / \mathrm{kg}$ of ethanol at 90 days of age. In addition, they differed in their response to such stressors as cardiac puncture and noise/cage shake. Of particular interest, however, is the finding that alcohol-treated offspring aged 75-100 days did not differ from controls in their pituitary-adrenal response to being placed in a cold room for $60 \mathrm{~min}$. Taken together, these findings indicate that a number of physiological measures normally associated with stress are enhanced in pups exposed to alcohol prenatally. The fact that alcohol-treated animals, when adult, were no more sensitive than controls to the cold stressor indicates that alcohol-treated animals do acquire normal thermoregulatory abilities, even though they may be delayed in such development (Taylor, Branch, Kokka, \& Poland, 1983). This is in accord with a hypothesis linking the hyperactivity seen in juvenile alcohol-treated offspring with an initial absence of thermoregulatory ability. In addition to acquiring the ability to thermoregulate, the hyperactivity evidenced by treated offspring disappears (Abel, 1982; Bond, 1981; Riley, 1982).

The present findings indicate that pups exposed to alcohol prenatally are hyperactive at 16 and 22 days but not at 10 or 28 days when tested on their own in a novel environment. Furthermore, alcohol-treated pups react to the presence of home-cage shavings in the same way as control pups. However, the differences in activity are abolished if the animals are tested at $33^{\circ} \mathrm{C}$. The latter finding suggests that the hyperactivity observed at 16 and 22 days may be due in part to the alcohol-treated pups' being under greater thermal stress when isolated from their dam and littermates.

\section{REFERENCES}

Abel, E. L. (1981). Behavioral teratology of alcohol. Psychological Bulletin, 90, 564-581.

Abel, E. L. (1982). In utero alcohol exposure and developmental delay of response inhibition. Alcoholism: Clinical and Experimental Research, 6, 369-376.

Abel, E. L., \& Greizerstein, H. B. (1979). Ethanol-induced prenatal growth deficiency: Changes in fetal body composition. Journal of Pharmacology \& Experimental Therapeutics, 211, 668-671.
Allin, J. T., \& Banks, E. M. (1971). Effects of temperature on ultrasound production in rodents. Developmental Psychobiology, 4, 149-156.

Bond, N. W. (1981). Prenatal alcohol exposure in rodents: A review of its effects on offspring activity and learning ability. Australian Journal of Psychology, 33, 331-344.

Bond, N. W. (1984). Behavioural teratology: Fetal alcohol exposure and hyperactivity. In N. W. Bond (Ed.), Animal models of psychopathology (pp. 279-311). Sydney \& New York: Academic Press.

Bond, N. W., \& DiGiusto, E. L. (1977). Prenatal alcohol consumption and open-field behavior in rats: Effects of age at time of testing. Psychopharmacologia, 52, 311-312.

Bronstein, P. M., Marcus, M., \& Hirsch, S. M. (1978). The ontogeny of locomotion in rats: The influence of ambient temperature. Bulletin of the Psychonomic Society, 12, 39-42.

Buelke-Sam, J., Sullivan, P. A., Kimmel, C. A., \& Nelson, C. J. (1984). Sex and strain differences in the developmental activity profile of the rat tested over clean vs home cage bedding. Developmental Psychobiology, 17, 67-77.

Campbell, B. A., Lytle, L. D., \& Fibiger, H. C. (1969). Ontogeny of adrenergic arousal and cholinergic inhibitory mechanisms in the rat. Science, 166, 637-638.

CAmpbell, B. A., \& Raskin, L. A. (1978). Ontogeny of behavioral arousal: The role of environmental stimuli. Journal of Comparative \& Physiological Psychology, 92, 176-184.

Ewart, F. G., \& Cutler, M. G. (1979). Effects of ethyl alcohol on behavior in nursing female mice. Psychopharmacologia, 66, 143-146.

Fowler, S. J., \& KELlogG, C. (1975). Ontogeny of thermoregulatory mechanisms in the rat. Journal of Comparative \& Physiological Psychology, 89, 738-746.

GoodRICK, C. L. (1975). Adaptation to novel environments by the rat: Effects of age, stimulus intensity, group testing, and temperature. $D e$ velopmental Psychobiology, 8, 287-296.

Jones, K. L., Smith, D. W., Ulleland, C. N., \& Streissguth, A. P. (1973). Pattern of malformation in offspring of chronic alcoholic mothers. Lancet, 1, 1267-1271.

Landesman-Dwyer, S., Ragozin, A. S., \& Little, R. E. (1981). Behavioral correlates of prenatal alcohol exposure: A four-year followup study. Neurobehavioral Toxicology \& Teratology, 3, 187-193.

Lemoine, P., Harousseau, H., Borteryu, J.-P., \& Menuet, J.-C. (1968). Les enfants de parents alcooliques: Anomalies observees à propos de 127 cas. Quest Medicale, 21, 476-482.

Pappas, B. A., Vickers, G., Buxton, M., \& Pusztay, W. (1982). Infant rat hyperactivity elicited by home cage bedding is unaffected by neonatal telencephalic dopamine or norepinephrine depletion. Pharmacology Biochemistry \& Behavior, 16, 151-154.

RANDAlL, C. L. (1982). Alcohol as a teratogen in animals. In Biomedical consequences of alcohol use (Alcohol and Health Monograph No. 2., U.S. Dept. of Health and Human Services No. (ADM) 82-1191, pp. 311-332). Washington, DC: U.S. Government Printing Office.

RILEY, E. P. (1982). Ethanol as a behavioral teratogen: Animal models. In Biomedical consequences of alcohol use (Alcohol and Health Monograph No. 2., U.S. Dept. of Health and Human Services No. (ADM) 82-1191, pp. 311-332). Washington, DC: U.S. Government Printing Office.

Shaywitz, S. E., Cohen, D. J., \& Shaywitz, B. A. (1980). Behavior and learning difficulties in children of normal intelligence born to alcoholic mothers. Journal of Pediatrics, 96, 978-982.

Taylor, A. N., Branch, B. J., Cooley-Matthews, B., \& Poland, R. E. (1982). Effects of maternal ethanol consumption in rats on basal and rhythmic pituitary-adrenal function in neonatal offspring. Psychoneuroendocrinology, 7, 49-58.

Taylor, A. N., Branch, B. J., \& Kokka, N. (1981). Neuroendocrine effects of fetal alcohol exposure. Progress in Biochemical Pharmacology, 18, 99-110.

Taylor, A. N., Branch, B. J., Kokka, N., \& Poland, R. E. (1983). Neonatal and long-term neuroendocrine effects of fetal alcohol exposure. Monographs in Neural Science, 9, 140-152.

(Manuscript received June 12, 1985; revision accepted for publication December 2, 1985.) 